Carlos Mario Rodríguez Rodríguez*

\title{
Ciudades sensoriales. Revisión de proyectos de interpretación sensorial urbana ${ }^{1}$
}

\author{
Sensory cities. Review of urban sensory \\ interpretation projects \\ Cómo citar: \\ Rodríguez, C. M. (2017). Ciudades sensoriales. Revisión de proyectos de interpretación sensorial \\ urbana. Designia, 4(2), 37-59.
}

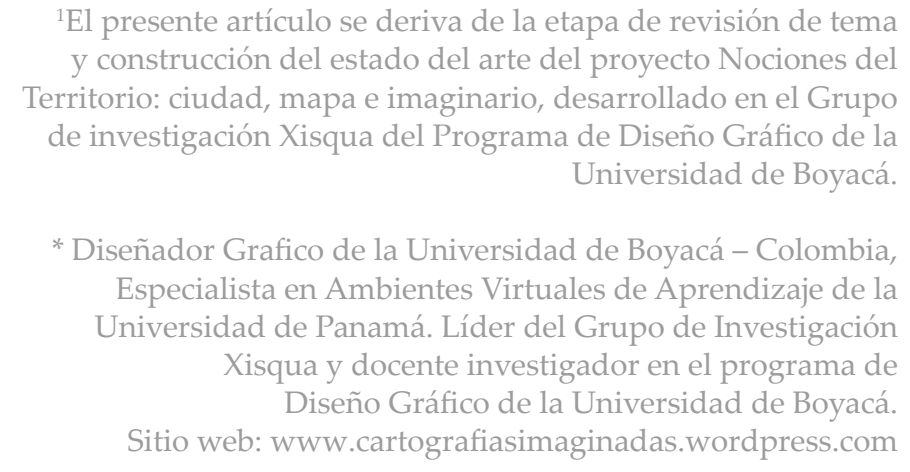

${ }^{1} \mathrm{El}$ presente artículo se deriva de la etapa de revisión de tema corritorio: de investigación Xisqua del Programa de Diseño Gráfico de la Universidad de Boyacá.

Especialista en Ambientes Virtuales de Aprendizaje de la Universidad de Panamá. Líder del Grupo de Investigación Xisqua y docente investigador en el programa de Diseño Gráfico de la Universidad de Boyacá. Sitio web: www.cartografiasimaginadas.wordpress.com
Palabras clave:

Ciudad, percepción, paisaje urbano, mapeo sensorial.

\section{Key words:}

City, perception, cityscapes,

sensory mapping.

Recibido: 25/07/2016

Aceptado: 29/11/2016

\section{Resumen:}

En el presente documento se realiza una revisión temática en torno a proyectos internacionales y locales cuyo objetivo ha sido la interpretación de la ciudad a partir de los sentidos. Se han considerado estudios multidisciplinares y experiencias que permiten reconocer en la ciudad un objeto de estudio de gran riqueza interpretativa y múltiples posibilidades y perspectivas de análisis. 


\section{Abstract:}

This paper offers a thematic review of international and local projects aiming to interpret the city from the senses. Multidisciplinary studies and experiences in which the city emerges as a study object plenty of interpretive possibilities and perspectives for analysis have been considered.

\section{INTRODUCCIÓN}

De parte a parte parece que la ciudad continuara en perspectiva multiplicando su repertorio de imágenes: en cambio no tiene espesor, consiste solo en un anverso y un reverso, como una hoja de papel, con una figura de este lado y otra del otro, que no pueden despegarse ni mirarse.

(Las ciudades y los Ojos 5, en Las ciudades invisibles)

Italo Calvino (2012)

Las ciudades son como los libros, están abiertas al descubrimiento, son interesantes, intrincadas, divertidas y tristes. Las ciudades se recorren, se conocen y se memorizan, sorprenden y aburren. Las ciudades, como los libros, están dispuestas a la lectura. Pero, ¿cómo leer una ciudad? Para ello no basta repasar su historia o conocer sus planes de desarrollo a futuro; leer la ciudad implica vivirla, porque como gran contexto generador de estímulos, requiere para su percepción y lectura el uso de los cinco sentidos. Leer las ciudades es entender que ellas se sienten, se huelen, se saborean, se escuchan y se ven.

El interés generado por los procesos de desarrollo de las ciudades ha evidenciado la multiplicidad de disciplinas para las que el entorno urbano es un objeto de estudio válido. Así, desde la comunicación, el diseño, la psicología y el arte, entre otras, se han realizado proyectos cuyo objetivo común ha sido articular una visión de la ciudad. Precisamente, uno de los intereses del grupo de investigación Xisqua de la Facultad de Arquitectura, Diseño y Urbanismo de la Universidad de Boyacá ha sido estudiar la imagen de la ciudad como reflejo de la cultura y la identidad de sus habitantes. En este sentido y dada la naturaleza interdisciplinar del grupo, el tema ha sido abordado desde diferentes acepciones y perspectivas que hasta el momento han permitido proyectar la imagen de municipios del departamento de Boyacá, tales como Tibasosa, Morcá (Sogamoso), Duitama y Tunja. 
${ }^{1}$ Este documento está

fundamentado en el estado del arte estructurado en los proyectos "Formas de la ciudad imaginada", "Colores de la ciudad imaginada" y "Sabores de la ciudad imaginada".

${ }^{2}$ El grupo Xisqua realiza sus proyectos bajo la línea de investigación Diseño del Mensaje Visual.
Con base en esta premisa y tomando en consideración el estado del arte que se ha construido en algunos proyectos del grupo, en este documento se revisaron estudios en torno a la ciudad y su interpretación desde los sentidos ${ }^{1}$, con especial énfasis en aquellos generados en la comunicación, el mensaje visual y la estética, de acuerdo con la línea de investigación desde la que actúa Xisqua². De esta manera se han articulado trabajos que más allá de ser un grupo ecléctico de desarrollos sobre la urbe, siguen un hilo conductor centrado en buscar maneras de interpretarla y descubrirla. Cada uno lee un entorno y a partir de metodologías particulares, proyecta perspectivas de este objeto de estudio interminable.

\section{LOS CINCO SENTIDOS EN LA CIUDAD}

Uno de los primeros referentes que se ha tomado en consideración en esta revisión es el proyecto editorial Bogotá, cinco sentidos (Salas Silva, Ávila y Quiroz, 2003), el cual efectuó una interpretación de Bogotá a partir de los sentidos. La metodología empleada en esta publicación experimental consistió en reunir escritores, fotógrafos y artistas, quienes fueron invitados a descubrir la capital del país por medio de tacto, vista, oído, olfato y gusto. De tal modo, se siguieron tres ejes (escritura, registro fotográfico y obra artística), es decir, por cada sentido se articularon tres interpretaciones distintas que configuraron la lectura de la ciudad.

En el sentido del olfato, por ejemplo, la exploración fotográfica reflexionó acerca de los olores de la calle y los recintos. Se evocaron los olores del pino y del eucalipto, la laca de los salones de belleza, el betún, el pollo de los asaderos, el humo de los buses y la basura. De la misma manera, mediante un recorrido se registraron fotografías del suelo y desde el tacto se planteó un ejercicio de calco que incluyó la textura de un andén de la ciudad.

En el abordaje de la vista, la imagen de la ciudad fue plasmada en el color naranja de las fachadas de ladrillo, el azul del cielo y el verde de los cerros. Asimismo, se reflexionó sobre el crecimiento y la transformación urbana. Por su parte, para la audición, la exploración se enfocó en los sonidos cotidianos: los megáfonos de los payasos que anuncian un restaurante, las máquinas de construcción y las bocinas de los buses conformaron ese panorama. A su vez, el artista Nadín Ospina hizo una metáfora de la "ciudad desconocida" a partir del símbolo del caracol. 
Por último, respecto al sentido del gusto, los personajes relacionados con la gastronomía urbana de la capital fueron registrados fotográficamente: comensales, administradores, cocineros, meseros y carniceros, entre otros, fueron retratados como los actores urbanos del sabor de Bogotá. En el mismo eje temático, Rodrigo Facundo elaboró una recopilación de la gráfica popular presente en restaurantes de sectores populares. Es destacable la diversidad de culturas plasmadas en las pinturas de estos establecimientos, lo cual muestra a Bogotá como epicentro para la convergencia de sabores de todas las regiones del país.

Esta publicación es un referente metodológico y proyectual que además de presentar distintas formas de comprender la ciudad desde la percepción, lleva las experiencias al campo gráfico y visual en un producto editorial que emplea el registro fotográfico y la narración urbana como herramientas para la captura de las sensaciones generadas por la urbe.
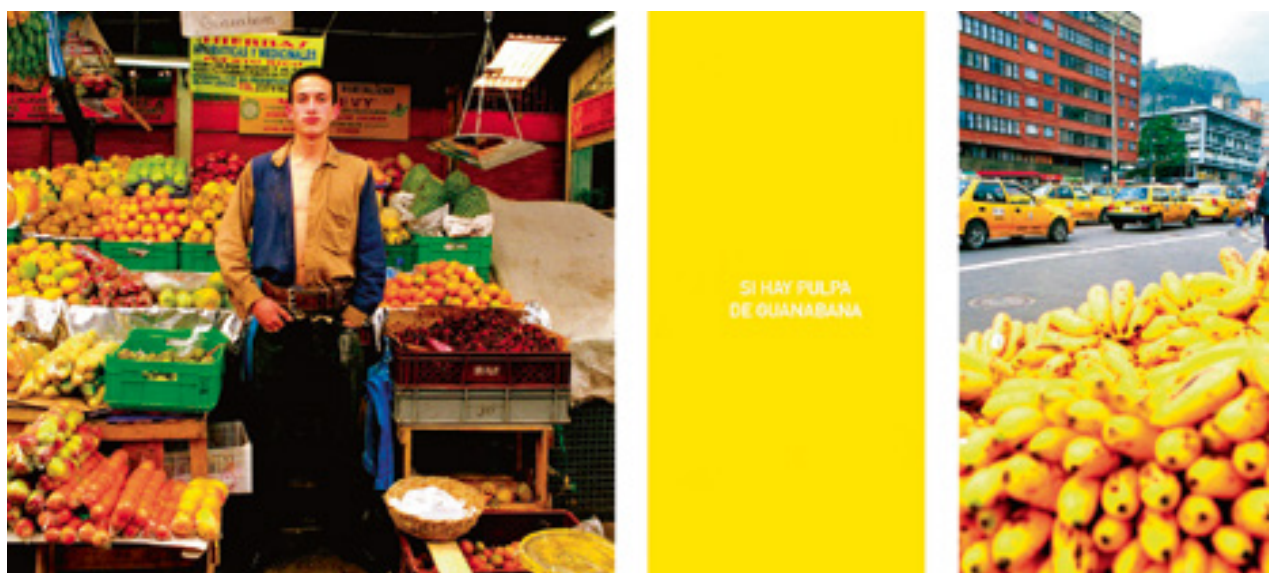

Figura 1. Páginas del libro Bogotá cinco sentidos.

Fuente: www.flickr.com/photos/bogotacincosentidos

Desde la misma línea investigativa actúa el colectivo colombiano Popular de lujo, que lleva más de una década registrando la gráfica popular de Bogotá y algunas zonas de Colombia. Actualmente, su archivo agrupa fotografías y estudios inspirados en la cultura popular y la identidad colombiana. Este grupo se ha especializado en el registro de intervenciones populares sobre las paredes, ya sean pintadas, rotuladas o en avisos, que han ido tatuando la piel de la ciudad con manifestaciones que más allá de vender o publicitar un producto se han convertido en expresiones de la cultura popular y la identidad local urbana. 


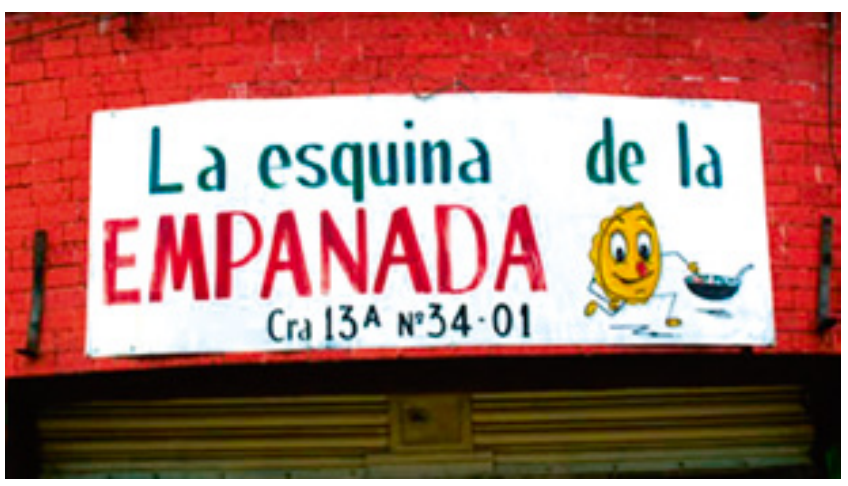

Figura 2. Eres lo que comes.

Fuente: www.populardelujo.com

Popular de lujo ha adoptado como principal medio de difusión internet. Su sitio web y blog dan cuenta de sus procesos, la información que recolectan y las colaboraciones recibidas de investigadores externos. De igual forma, reseñan investigaciones relacionadas con la identidad local expresada en la cotidianidad y las costumbres del ciudadano, desde un enfoque que si bien es generalmente visual, también contempla sentidos como el gusto.

Entre estos trabajos se encuentran Mesa 19 de Ana Delgado (Popular de Lujo, 2000a), exploración fotográfica de la estética de los restaurantes del centro bogotano en que se reconoce por medio de la lente de la investigadora los elementos intrínsecos en estos espacios ampliamente usados por los habitantes. Eres lo que comes (Popular de Lujo, 2000b) de Johanna Villamil, Katerine Trejos, Gina Baquero y Lorena Zambrano, es un estudio de carácter experimental de gestión urbana e interacción cultural sobre la iconografía de los avisos de comidas rápidas. A partir de la visualidad da cuenta de elementos cotidianos de la identidad de Bogotá, por ejemplo, la importancia de la popular empanada como el pasabocas por excelencia que permea todas las clases sociales y existe en todos los sectores. Igualmente, costumbres santafereñas como las onces con chocolate y el tinto se contrastan con platos como la bandeja paisa y el pargo rojo, provenientes de otras regiones del país pero ya incorporados a la idiosincrasia y las características multiculturales de la capital. 


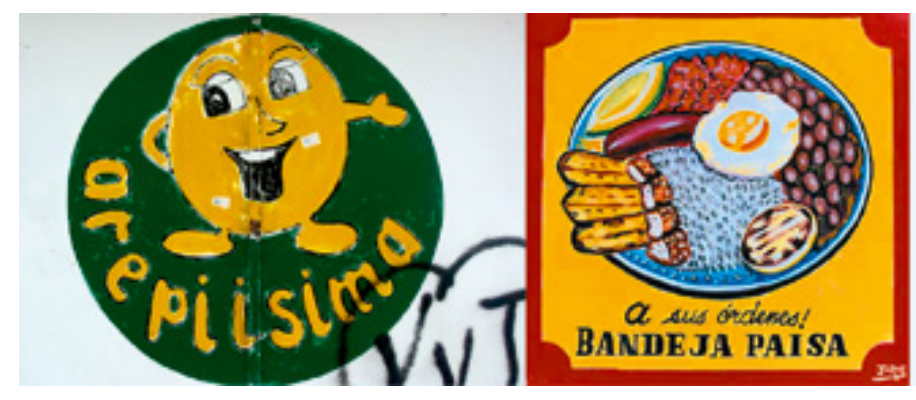

Figura 3. Registros fotográficos del banco de imágenes de Popular de Lujo. Fuente: www.populardelujo.com

\section{LA MIRADA EN LA CIUDAD}

Una de las herramientas empleadas con más frecuencia y eficacia en estos estudios es la fotografía, método por medio del cual se han capturado instantes en el tiempo que no solo retratan la ciudad, pues en muchos casos, han llegado a ser una radiografía del momento histórico en que se realizó la captura.

A propósito del trabajo fotográfico se revisaron dos referentes, uno internacional y otro local. El primero, realizado por el fotógrafo Horst Hamann (2001) en New York Vertical, hace una interpretación visual de Nueva York a partir del concepto de la verticalidad. El lenguaje manejado por Hamann se presenta como un recorrido urbano que usa diversos enfoques y lugares para mantener la verticalidad en el registro fotográfico. Es significativo el tratamiento del encuadre como hilo conductor de esa verticalidad característica de Nueva York, es decir, un concepto que se traduce a una forma particular de concebir y observar la ciudad. A su vez, la forma del diseño en el producto final da lugar a un libro en su mayoría visual cuyas fotografías están precedidas por frases referentes a la megaurbe estadounidense, un reflejo del pensamiento de quienes la habitan o visitan. 

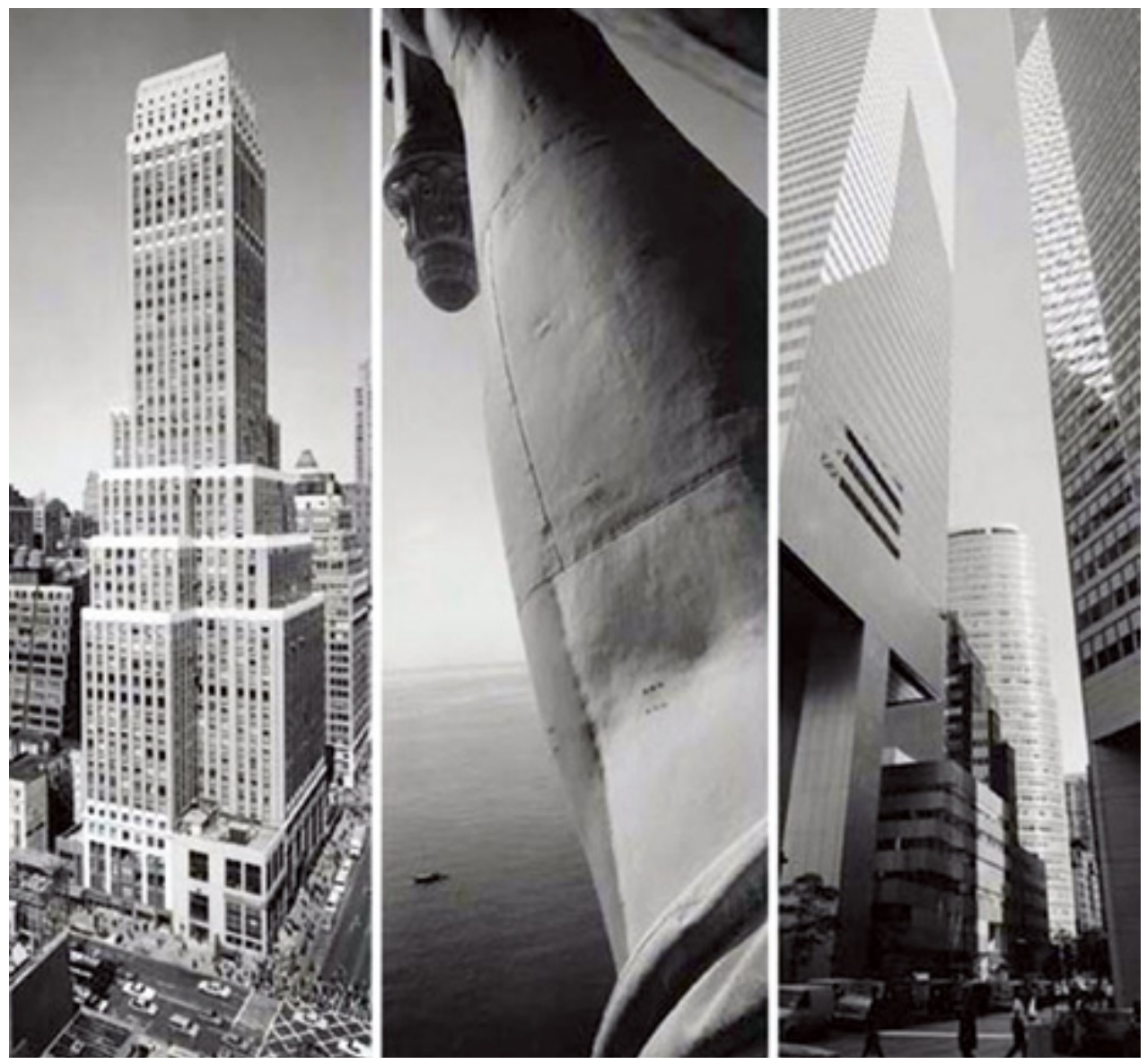

Figura 4. Fotografías del libro New York Vertical.

Fuente: Hamann (2001).

En el contexto local, Metamorfosis de una ciudad (Museo de Bogotá, 2005), trabajo fotográfico de Paul Beer sobre Bogotá, elabora un discurso en torno a su percepción del entorno. De forma similar a New York Vertical, se fundamenta en la técnica fotográfica y constituye un lenguaje particular del autor. Sin embargo, a diferencia del trabajo de Hamann, Beer no presenta la capital como una muestra del instante sino como un viaje a través del tiempo y de las transformaciones que ha sufrido con el paso de los años; por consiguiente, la obra desarrolla una mirada particular del entorno, centrada en la evolución de la arquitectura capitalina. 

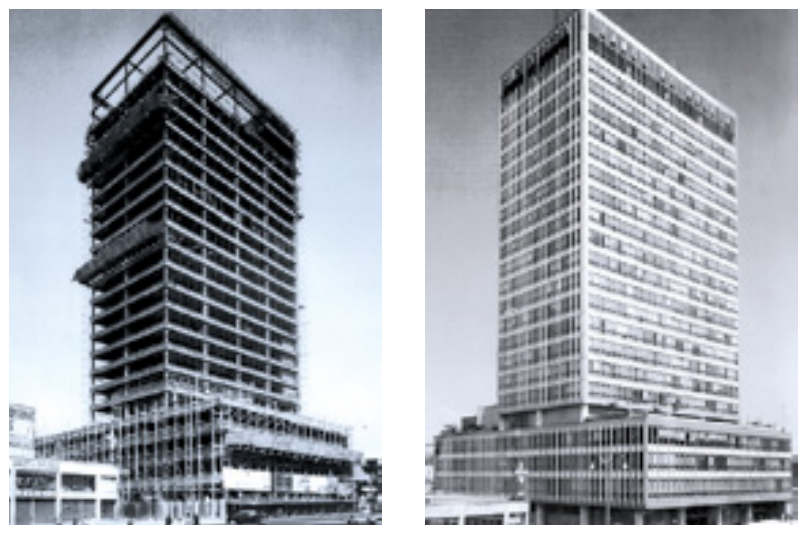

Figura 5. Fotografías del Edificio del Banco de Bogotá en 1956 (izquierda) y 1963 (derecha). Fuente: Museo de Bogotá (2005).

El grupo Xisqua ha llevado a cabo proyectos en Tunja, con especial interés en la imagen de la ciudad, apoyados en la comunicación visual y en la metodología de los imaginarios urbanos. De tal modo, se han establecido configuraciones desde la perspectiva de los propios habitantes.

De la ciudad me sé su olor: aproximaciones visuales y otros sentidos, Tunja (Guerrero, 2012) es un resultado de la investigación Imagen de ciudad nuevo patrimonio, en el cual la autora se centró en la indagación sobre la imagen de la ciudad y su relación con el habitante, a partir de la identificación de categorías visuales y estéticas. El trabajo de campo y el ejercicio de observación de la cotidianidad se traducen en aproximaciones visuales que en la publicación están divididas en tres ejes de análisis. En primer lugar, las intervenciones efímeras sobre la urbe, correspondientes a objetos que en cierto momento rompen con la uniformidad del entorno; en segundo lugar, la ciudad intervenida desde lo gráfico, cuya interpretación se basa en la semiótica urbana; por último, un espacio donde los personajes cobran vida gracias a la ilustración y la poesía. Se trata de un diálogo entre reconocidos elementos del imaginario tunjano, tales como monumentos, casas y pinturas, o simplemente aquellos rescatados del diario discurrir, como un andén, la basura o un perro callejero. Todos fueron personificados a partir de las historias urbanas y unidos por la metáfora del perro, un ser que al recorrer cada rincón reconoce recuerdos, rutas, lugares y olores. 


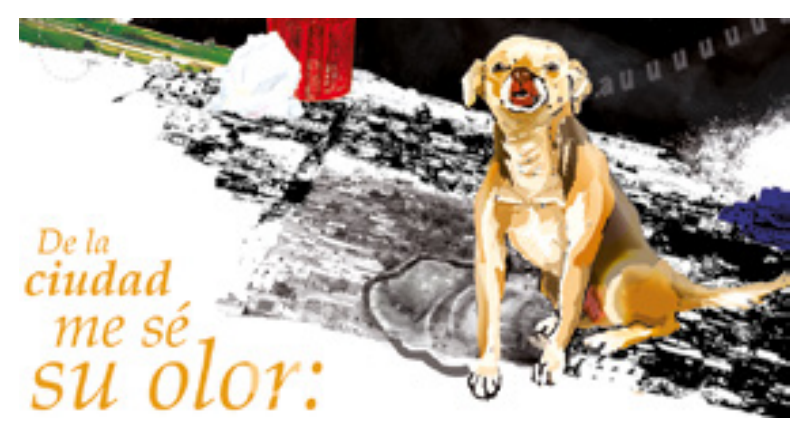

Figura 6. Ilustración en De la ciudad me sé su olor: aproximaciones visuales y otros sentidos, Tunja. Fuente: Guerrero (2012).

\section{AROMAS DE CIUDAD}

El abordaje a la ciudad desde la visualidad es el más frecuente entre los estudios revisados, al superar en cantidad a exploraciones desde el sonido o el olor, menos recurrentes. Aun así, estas últimas constituyen acercamientos con gran rigurosidad, pertinencia e innovación. En relación con los olores, en el estudio de los imaginarios urbanos de Bogotá, Silva (2003) articula una lectura de los aromas que se esparcen en la capital y la consigna en las páginas de Bogotá Imaginada.

La metodología aplicada por Silva incluye la recolección de información a partir de encuestas, fotografías y videos, material que conduce a identificar la relación de los habitantes con el entorno urbano y a presentar a la ciudad en su esencia. El imaginario es el lazo que une a un espacio con sus habitantes, es una apropiación de los lugares y una resignificación a partir de la experiencia de ser ciudadano. En el capítulo "La Ciudad" se reflexiona acerca de la evolución de los ritos cotidianos de los bogotanos y de los cambios que han experimentado sus costumbres con el tiempo, en la medida que estas se adaptan a nuevos escenarios. Asimismo, se indaga sobre las percepciones de miedo y gusto a partir de la relación de espacios y sentidos, para conformar un croquis de los olores de Bogotá.

Los malos olores tienden a relacionarse con el peligro y la pobreza, representados por lugares como el cartucho y la zona industrial, como también con la venta de comidas callejeras. Por su parte, los mejores olores se perciben en espacios abiertos y en sectores de estratos más altos como el Parque de la 93, asociación que es complementada con una percepción de seguridad, belleza y bienestar. Es importante notar que la relación del olor con el nivel socioeconómico del sector es reconocida por personas de estratos altos y bajos, es decir, residentes de barrios de bajo estrato en ciertos casos vinculan su propio entorno a olores no deseables. 
Otro horizonte de análisis se enfoca en las panaderías como lugares de gran importancia para el ciudadano. En Bogotá y en muchas ciudades colombianas es notable la proliferación de este tipo de establecimientos que se han hecho indispensables en la configuración de los barrios. Generalmente también funcionan como cafeterías y se asocian con buenos olores, sensaciones de bienestar y seguridad. Ofician como sitios de encuentro y reunión y a pesar de que en las últimas décadas parecen haber perdido popularidad, su tradición hace parte del acervo bogotano y siguen siendo espacios significativos y de recordación.

Es importante resaltar la relación que se establece entre la percepción a través de los sentidos primarios (como el olfato) con imaginarios y características que se otorgan a determinados lugares y sectores. Es así como por medio de los buenos o malos olores los ciudadanos establecen preferencias y rechazos, asociaciones a miedo y seguridad y relaciones socioeconómicas con el entorno.

Con un enfoque similar, Kate McLean (2014), investigadora sensorial y diseñadora, ha enfocado sus estudios en el descubrimiento de las narrativas de lugar que se esconden desde la perspectiva de los cinco sentidos. Uno de sus trabajos con mayor impacto es el Mapa de los aromas de París, propuesto como una estrategia didáctica para explorar la capital francesa y crear un nuevo mapa de ella a partir de experiencias personales que pueden llegar a evocar sus olores. La metodología empleada comenzó con la pregunta “¿cuál es el aroma que recuerda de París?”. Este interrogante se formuló a residentes y parisinos que no residen en la ciudad, como parte de cortas entrevistas que permitieron establecer los primeros lugares significativos para el trabajo de campo. Se analizaron así lugares específicos y se desarrollaron esencias artificiales que capturaron los olores hallados con el apoyo de expertos en química de olores. Con este material se elaboró un primer mapa que hizo parte de una exposición y con el cual los visitantes podían interactuar, al igual que con las esencias, para escribir luego notas personales sobre sus recuerdos particulares. Se construyó a continuación un mapa con los 14 aromas que caracterizan a París y las narrativas de los lugares con que estos se relacionan. Fue posible establecer que el olfato, en particular, tiene una estrecha relación con la memoria y las relaciones de agrado o rechazo hacia determinadas zonas. 


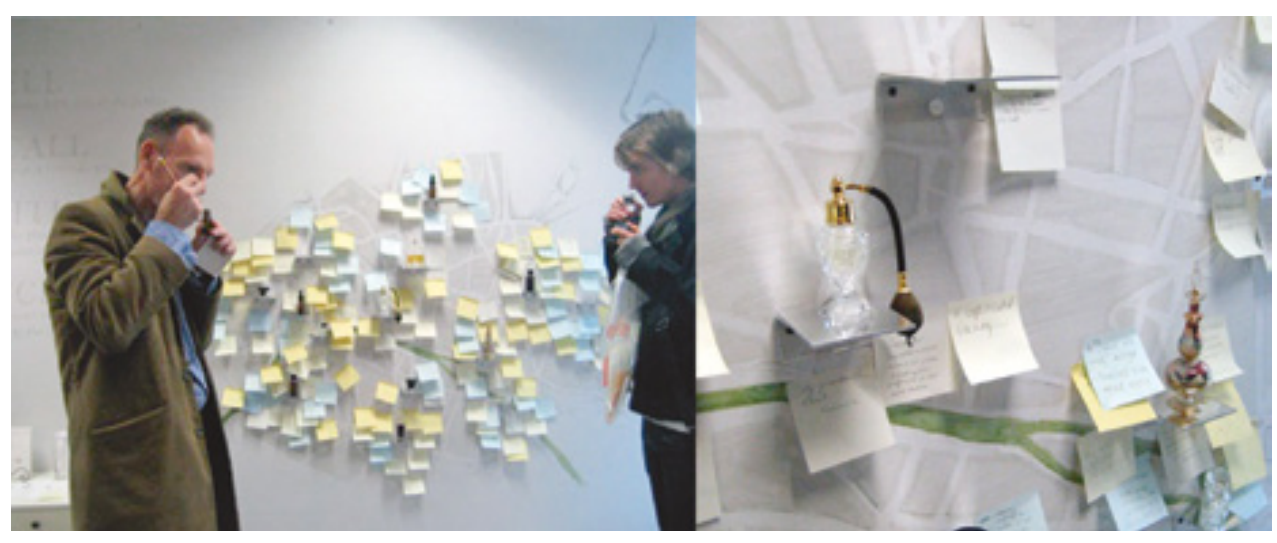

Figura 7. Intervención sobre el mapa de olores de París a partir de notas adhesivas y esencias artificiales.

Fuente: NANO New American Notes Online (http://www.nanocrit.com/ issues/6-2014smell-map-narratives-place-paris).

En Colombia, algunos medios se han cuestionado por el sentido del olfato y su relación con la ciudad. Entre ellos, el periódico El Tiempo (2014) en la sección Zona, llevó a cabo una experiencia en que periodistas y expertos en química de olores realizaron un trabajo de campo a partir de la pregunta "¿a qué huele Bogotá?". Mediante la visita a ocho sectores concurridos se logró una caracterización de un paseo olfativo que concluyó con una infografía y crónicas escritas desde la experiencia sensorial de cada reportero. De manera similar, Ana María Páez y Carolina Hernández (2014) en el documental Son tus aromas: Bogotá, recorrieron seis lugares de la capital para identificar aromas como aquellas del pino y la tierra húmeda en el Parque Nacional, el incienso y la madera en la Iglesia de Santa Clara, papa, yuca, cilantro, pescado, claveles y lirios en la Plaza de Mercado de Paloquemao. Al registrar también las emociones conectadas con las aromas, la experiencia demostró que por medio de buenos o malos olores el olfato vincula emocionalmente los lugares y lleva a definir preferencias y rechazos, asociaciones al miedo y la seguridad y relaciones socioeconómicas con el entorno.

\section{LA PIEL DE LA CIUDAD}

En relación con el tacto, la revisión se remitió a un proyecto dedicado al estudio de la piel de la ciudad, entendida como la apropiación que hacen los habitantes por el espacio (paredes, fachadas, cuadras, senderos) y las manifestaciones estéticas surgidas como parte de la necesidad de las personas por humanizar el entorno. 
El enfoque de Expresiones estéticas del hábitat dentro de una comunidad barrial en transformación: la Piel del Morro (Echeverri Arango, 2007) se basó en una mirada estética de la configuración del paisaje urbano del barrio Moravia en los sectores de El Morro y El Oasis, en Medellín, formados en torno a la principal montaña de basura que constituye la fuente de ingreso a través del reciclaje para sus habitantes.

La mirada a este barrio se dio a partir de la relación existente entre las prácticas culturales de los ciudadanos, la construcción y la apropiación de un sector surgido desde la basura, donde se han levantado hogares de invasión y con difíciles condiciones geográficas, sociales y ambientales. Desde la mirada de Echeverri, la piel de la montaña ha sido humanizada en la práctica de un bricolaje en constante mutación, en construcciones que crecen o se destruyen, en una arquitectura del desecho que forma un collage de materiales y formas, más allá de conceptos como bonito o feo, pues la motivación de quienes las construyen es la supervivencia.

Esta apreciación estética de la realidad humana empleó como herramientas metodológicas la observación y el contacto con el objeto de estudio, en tanto obtuvo y registró su información mediante fotografía y entrevistas con habitantes del sector. Asimismo, el análisis decantó tres fenómenos principales (constructivos, sociales y corporales), mientras que un video documental priorizó en los residentes y sus maneras de habitar este espacio.

Este tipo de estudios revelan cómo mediante la estética es posible identificar la cotidianidad de un grupo de habitantes, sus prácticas, comportamientos y costumbres, y cómo estas manifestaciones evidencian nociones del gusto de las personas, sus maneras habitar, expresarse y apropiarse del espacio.

\section{SABORES DE CALLES Y RECINTOS}

La riqueza gastronómica propia de las ciudades latinoamericanas ha posibilitado investigaciones generalmente de carácter antropológico y social cuyo propósito ha sido documentar y rescatar sabores y saberes culturales. Sin embargo, la revisión en este trabajo se ha enfocado en experiencias que si bien se han apoyado en el patrimonio gastronómico, lo han abordado desde una mirada visual y estética con el fin de relacionar el sentido del gusto y la identidad de las ciudades. 
En Barcelona, el proyecto Food Cultura, emprendido por los investigadores Antoni Miralda y Montsé Guillén (2011), consistió en una colección de objetos y experiencias que dan cuenta de intervenciones y actividades en torno a la relación de la gastronomía con la cultura de distintas ciudades iberoamericanas.

Vajilla imaginaria y Sabores y lenguas son dos proyectos interrelacionados que desde hace más de una década convocan a artistas, investigadores, expertos en gastronomía y ciudadanos en general a reflexionar en torno a las ciudades como contenedoras de los gustos, la memoria y la historia de sus habitantes. En Vajilla imaginaria, bajo la metáfora de convocar a la gente a la mesa, se invitó a intervenir un plato blanco a partir del imaginario de sus autores, las experiencias vividas, los recuerdos de aromas y sabores, fantasías y anhelos urbanos. La exposición de las vajillas está ligada a Sabores y lenguas, estudio fundamentado en la participación de las personas que se propone estructurar una matriz de sabores y lugares, los cuales son consignados por los visitantes a la exposición en pizarras y alrededor de grandes lenguas que actúan como elemento iconográfico de la muestra.

La información recopilada nutre el archivo web de Food Cultura, el cual tiene como objetivo rescatar las tradiciones locales y autóctonas de recetas, ingredientes y refranes que se ven opacados en la actualidad por la globalización y la proliferación de comidas rápidas y franquicias de restaurantes extranjeros. Para Miralda, (2011) “la cultura no se encuentra aislada tras las paredes de las instituciones, sino que está en la esfera del dominio público y en los ritos sociales compartidos. Entre estos, en primer lugar, el de compartir la comida" (http://www.foodcultura.org).

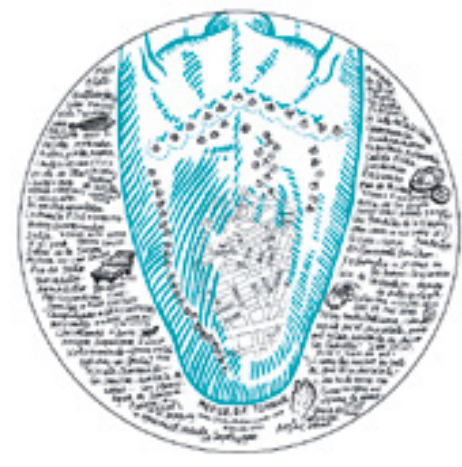

Figura 8. Sabores y lenguas: imagen de la exposición itinerante. Fuente: http://www.foodcultura.org/2012/09/06/sabores-y-lenguas-2/ 
Más que una obra artística, el proyecto de Antoni Miralda (2011) es una recopilación poética de la memoria y el acervo cultural de las sociedades por medio de los sabores locales. En palabras de Néstor García Canclini (2010):

\begin{abstract}
La investigación miraldiana recoge, con pasión etnográfica por los detalles, por lo singular, recetas y ritos, objetos de la cocina, de la mesa y de los mercados, lo que nutre y lo que publicita, el trabajo y la fiesta. Además de aportar una mirada lúdica a la antropología de la alimentación, innova en los relatos museológicos. Su Food Culture Museum no se dedica solo a preservar tradiciones; registra los discursos que las reinterpretan, adaptaciones para el turismo, posibilidades impensadas de reutilizar en otro contexto los sabores y vegetales que parecen solo arraigarnos a la tierra. La mirada de Miralda considera "patrimonio cultural" la vaca y los coches gigantescos de Texas, el maíz y el espantapájaros, lo que parece desunirnos por ser distinto en cada lugar (p. 6).
\end{abstract}

Este referente metodológico y conceptual ejemplifica procesos de participación ciudadana fundamentados en el trabajo colectivo y la convocatoria de saberes, al igual que propone una eficaz manera de traducir intangibles como el sabor en elementos de carácter visual (vajillas, pizarras y ollas en las exposiciones).

En el contexto local también se han efectuado exploraciones en esta categoría sensorial. Ejemplo de ello es Entre lo puro e impuro: representaciones iconográficas de Bogotá, del Colectivo de Investigación Gráfica y Visual de la Fundación Universitaria los Libertadores (Barbosa, Velázquez Osorio, \& Suárez Quintero, 2012). Esta investigación compiló y analizó cinco expresiones gráficas de Bogotá, una de ellas titulada Metáforas e íconos de la carne en Bogotá (Velázquez Osorio, 2010), la cual trató el tema de la representación de los productos de consumo derivados de la carne en la gráfica popular. A partir del estudio de avisos de este tipo, encontró elementos comunes en la representación del pollo o la vaca, como también características, actitudes y acciones frecuentemente asociadas a cada producto. 
Este proyecto sintetizó los rasgos comunes encontrados en los avisos de establecimientos de venta de carne (res, cerdo, pollo, pez) del centro de la capital y planteó lecturas de imaginarios sociales reflejados y connotados en la forma de representar la carne. Puntualizó en las coincidencias entre las categorías analizadas y definió niveles de significación en los que se compararon el contexto del producto, las connotaciones, los mensajes que emite y los recursos empleados para tal fin. Así, la res, el cerdo, el pez y el pollo se describieron desde una perspectiva urbana que los redefinió en el contexto bogotano. Por lo general, la res aparece como una representación amable, noble y distante, contraria al cerdo que es asociado a la fiesta o el carnaval y suele caricaturizarse. En el pollo se destacan conductas caníbales en tanto un carácter naturalista e idealizado caracteriza al pez.

Metodológicamente, este referente muestra un abordaje de diferentes elementos visuales y lecturas de las formas de apropiación de los ciudadanos por el entorno. De tal modo, examina desde la gráfica aspectos urbanos y socioculturales de Bogotá bajo el hilo conductor de las metáforas de la carne, en este caso la perspectiva desde la que se leen los contextos, las costumbres y las rutinas de consumo. El estudio ejemplifica a su vez cómo las representaciones de los animales o las mascotas de los establecimientos son un reflejo de las características de la sociedad que los consume, conformado por imaginarios urbanos en torno a conceptos como el campo, la gastronomía capitalina, la celebración y los sabores. Por otra parte, el trabajo reivindica la utilidad del registro fotográfico como testigo de las manifestaciones visuales captadas y posibilitador de su posterior análisis.

Análisis iconográfico del almuerzo popular "corrientazo" en la ciudad de Bogotá a partir de los conceptos percepto y afecto de Gilles Deleuze (Meléndez, 2012), es otra investigación en que el popular almuerzo capitalino "corrientazo" es visto como símbolo social y parte de la identidad de una clase social que permea la ciudad entera. El autor propone una revisión histórica, desde el siglo XIX, de la evolución de la riqueza gastronómica de la capital, caracterizada en todos los periodos por reflejar las diferencias sociales de clase. El recorrido comprende desde los platos autóctonos hasta la llegada de la cocina internacional en los años noventa, que junto con la popularización de hipermercados, academias de cocina $\mathrm{y}$ restaurantes internacionales, introdujo nuevos sabores y aromas que poco a poco se han ido sumando a la riqueza gastronómica preexistente. En medio de tal diversidad, la comida tradicional es destacada como verdadero reflejo de la identidad, en la medida que traspasa el paso del tiempo y está presente en todas las clases. 


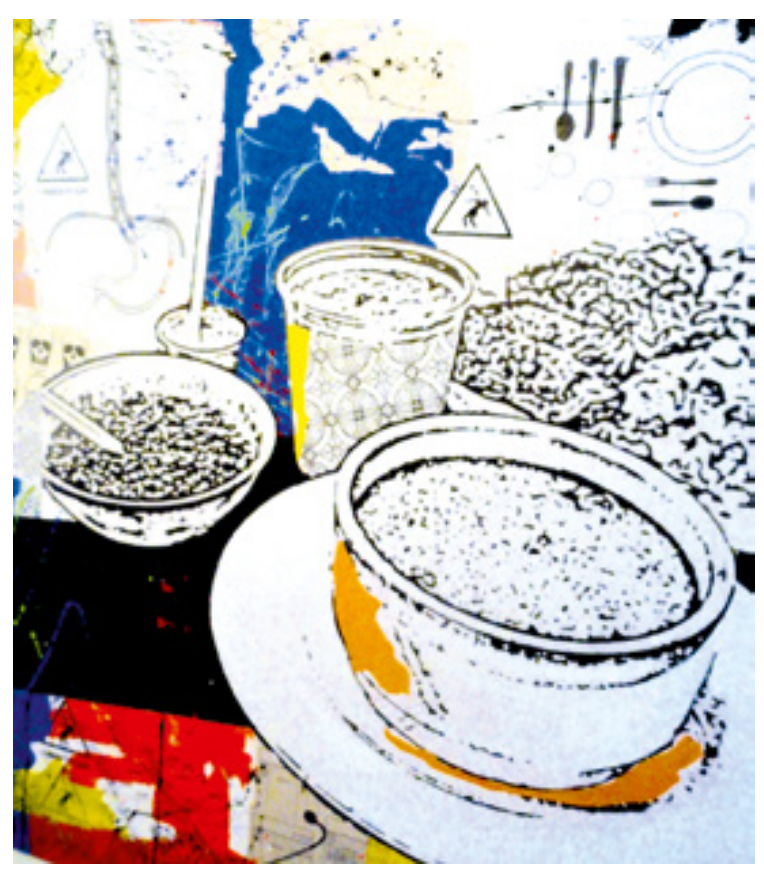

Figura 9. Fragmento del trabajo de Marcelo Meléndez. Fuente: fotografía del autor tomada en la exposición Proyecto Tesis, Museo de Arte Contemporáneo, Bogotá, 2012.

La investigación también estudia los enfoques desde los que se han abordado las significaciones sociales de la comida y pone de manifiesto que ingerir alimentos es un componente social por medio del cual se reflejan en gran parte las costumbres, la cultura, la herencia y la posición social. La relación comida - cultura está más allá de una simple necesidad fisiológica: es parte fundamental de las prácticas sociales del individuo, de su relación con el contexto y de la identidad de una comunidad. 
${ }^{3}$ En la página web

www.danielgoldaracena.com está consignado el material

sonoro recopilado por

el autor en diferentes

ciudades del mundo.

\section{ESCUCHAR LA CIUDAD}

Las ciudades son ruidosas por excelencia. Los megáfonos, los pitos y los carros hacen parte de su cotidianidad. Bastante se ha debatido sobre la contaminación auditiva y sus efectos nocivos en la salud, de modo que es común comparar la idea de paz y descanso con un lugar libre de ruido. Pero, ¿en qué punto puede este conglomerado auditivo llegar a diferenciar una ciudad de otra y ser parte de la identidad y la memoria de una sociedad? Precisamente, uno de los propósitos del proyecto de Daniel Goldaracena en Ciudad de México ha sido la construcción del patrimonio sonoro de esa capital. Durante 2010 y 2012, este realizador mexicano desarrolló un ejercicio exploratorio en que a partir de recorridos y visitas a los barrios más representativos de esa urbe capturó paisajes sonoros e instantes de la cotidianidad representados en los sonidos. Los resultados fueron presentados en la exposición Paisajes sonoros de los barrios de la ciudad de México, en que los registros sonoros fueron complementados con fotografías relacionadas con los instantes capturados. El trabajo mostró cómo a través del sonido se

\section{captura el peso de lo local (...) desde los trinos de los cientos de pájaros que al atardecer se resguardan en las copas de los árboles del Parque del Reloj en Polanco, hasta las alabanzas en honor a La Santa Muerte en el barrio de Tepito, pasando por el merolico que describe las bondades de una pomada para los pies, en el mercado de La Merced (Altamirano, 2013, www.bifurcaciones.cl).}

Esta lectura de ciudad, ahora perteneciente a la Fonoteca Nacional de México, es compilada por el autor en un sitio $w e b^{3}$ que además de presentar las exploraciones en la capital de dicho país, incluye un Book of Sounds que bajo la misma metodología ofrece paisajes sonoros de varias ciudades del mundo, a partir de la captura del instante por medio del sonido y la fotografía. 


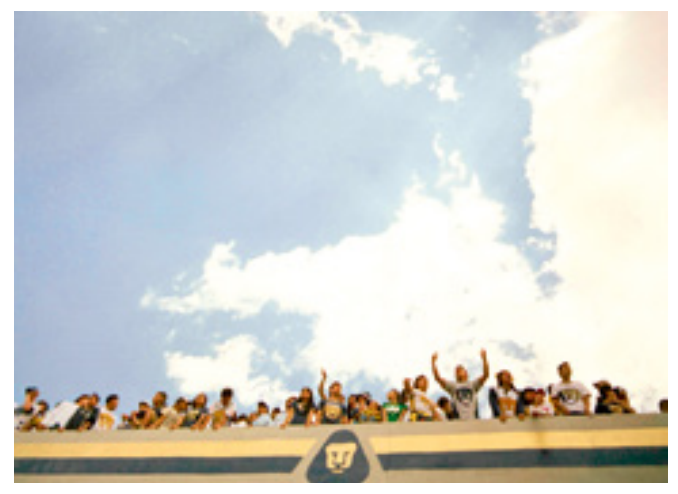

Figura 10. Estadio Universitario de México D.F., 2010.

Fuente: http://www.danielgoldaracena.com/ BookOfSound/book_of_sound.php

En Colombia, la Fonoteca Nacional emprendió el proyecto Mapa sonoro de Colombia, que a partir de referentes como Toronto, Nueva York y Londres, entre otros, se ha propuesto construir un mapa de los sonidos del país. Para ello, en una

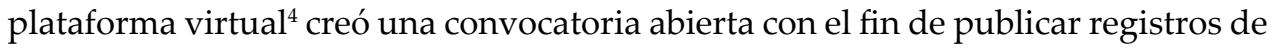
sonidos captados en el territorio nacional, los cuales dan cuenta de la cotidianidad, el contexto geográfico y las costumbres de los colombianos. Como respuesta a este llamado se planteó 200 efectos de sonidos urbanos de la ciudad de Bogotá (Castro, 2013), que mediante un trabajo de campo de dos meses buscó capturar la identidad sonora de la capital. La metodología se planteó como un estudio de descripción auditiva urbana consistente en recorridos desde los cuatro puntos cardinales, con líneas de estudio definidas: tráfico (motos, automóviles, estaciones), conversaciones (en centros comerciales, restaurantes, bares), plazas y naturaleza.

Como se describe en el archivo de Señal Memoria,

\footnotetext{
${ }^{4}$ En la página web

www.mapasonoro.fonoteca.

gov.co es posible escuchar

y publicar sonidos

registrados en todos los

rincones del país.
}

Los efectos de sonido que contiene este trabajo son el reflejo de la cultura bogotana, de la urbe, una ciudad que se caracteriza por su gran actividad social, económica y cultural. Son sonidos que identifican una sociedad y sus costumbres, un tiempo y un espacio, puesto que la información sonora registrada es única, teniendo en cuenta que los sonidos varían a través de los años por cambios en el medio ambiente, en la movilidad, en la industrialización y todas las demás transformaciones propias de una ciudad (Señal Colombia Sistema de Medios Públicos, 2013). 
Se registraron así vivencias en las calles bogotanas, voces de ciudadanos y sonidos como la lluvia o el tren de la Sabana que revelaron el potencial del registro auditivo como parte del patrimonio intangible de una ciudad, una forma de capturar el tiempo en que se identifica la urbe y sus costumbres en un espacio y época específica.

De manera similar, el colectivo Sonema se dedica al fomento de la experimentación y la exploración sonora en Bogotá. Su proyecto Bogonautas consiste en un mapa sonoro de la ciudad que desde una plataforma web se alimenta del trabajo colaborativo y la creación colectiva para recopilar el patrimonio auditivo capitalino, registrar sonidos de su cotidianidad y ubicarlos en el mapa. Otro de sus proyectos, Bogotá fonográfica, en asociación con la editorial Laguna Libros, fue propuesto a partir de la interpretación artística del sonido y planteó un viaje por la urbe mediante la percepción auditiva traducida a la expresión plástica en una apuesta por responder a la pregunta ¿a qué suena Bogotá? En este caso se convocó a 28 artistas plásticos colombianos quienes fueron invitados a "dibujar el sonido" a partir de un fragmento sonoro capturado en la ciudad, cuyo resultado dio cuenta de la riqueza y variedad acústica existente (Sonema, 2013).

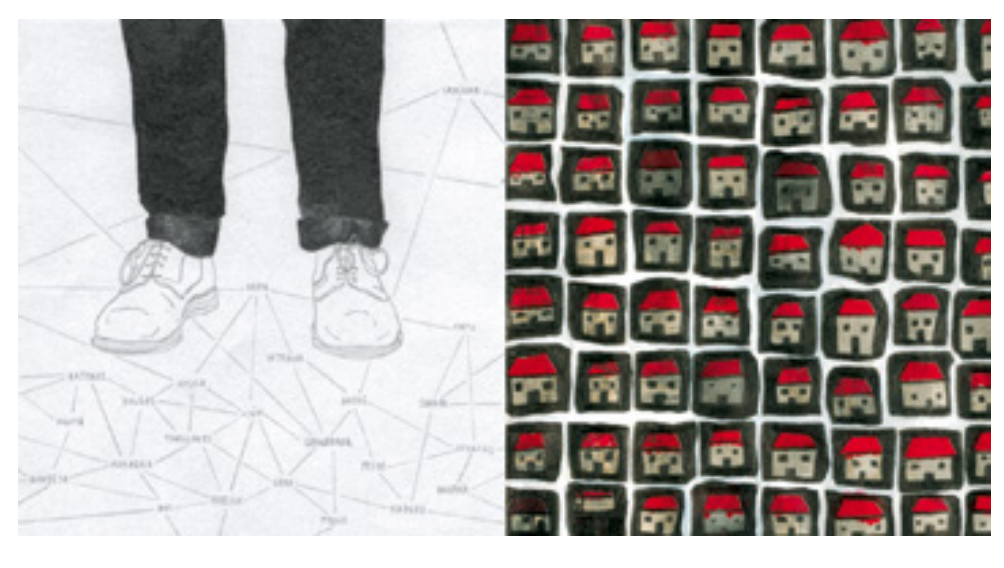

Figura 11. Postal del proyecto Bogotá fonográfica. Fuente: http://sonema.org/fonografica-19 
El producto de la investigación muestra el día a día de Bogotá mediante distintas expresiones gráficas del sonido en una serie de 32 postales, acompañadas de un mapa, enlaces de códigos QR y un libro de presentación del escritor Andrés Ospina, todo lo cual forma un kit para viajar por la capital. Al escudriñar entre una diversidad de ruidos, melodías y estruendos se descubre a qué suena:

\section{al camión de desperdicios, con su rugido desapacible de 2 a.m. A los "escobitas" que remueven la mugre de sus andenes cuando es demasiado temprano. Al pregón desesperado de la carrera 15 y sus "programas, juegos, películas". Suena a palomas, colibrís y copetones aleteando. A la llovizna y el sol de todos los días, clavados en un pavimento siempre maltrecho. $\mathrm{Al}$ polvo que se levanta bajo las gotas que empiezan a desgranarse para producir un almizcle arenoso que se cuela entre las fosas (Sonema, 2013).}

Los estudios referenciados en este documento se caracterizan por ser muestras espaciotemporales de la imagen de la ciudad, compuestas por manifestaciones de tipo visual, sonoro, olfativo, táctil y del gusto que más allá de ser lecturas urbanas, son formas de reconocimiento del valor patrimonial intangible de las urbes.

La revisión aquí realizada agrupó trabajos que desde los sentidos se relacionan con la imagen y la interpretación de la ciudad, un objeto de estudio de incontables posibilidades. Este recorrido por referentes que van desde ciudades de la magnitud de Nueva York hasta otras del contexto local como Tunja, demuestra que el tamaño o la importancia no determinan la pertinencia del proyecto, pues en urbes grandes, pequeñas e intermedias es posible reconocer su identidad y sus ciudadanos.

\section{A MANERA DE CONCLUSIÓN}

Uno de los objetivos de esta revisión fue compilar referentes que han sido citados en las investigaciones del grupo de Xisqua, por ello, el abordaje a la ciudad desde los sentidos ha sido el hilo conductor que permitió superar la diversidad de temáticas tratadas y enlazar esta información. La ciudad es un objeto de estudio que permite un abordaje multidisciplinar, por consiguiente, es pertinente desarrollar propuestas desde diversas miradas que como lo demuestran los proyectos citados, en su mayoría significan un aporte a la construcción de identidad, el reconocimiento de la cultura y la conservación del patrimonio intangible de las ciudades. 
Es posible deducir que existe un espíritu de la época que entiende a la ciudad como una experiencia multisensorial, no como un objeto de estudio aislado, ya que la relación del ciudadano con ella posibilita y abre el camino a sus múltiples lecturas.

Al hacer un balance, es mayor la cantidad de proyectos realizados desde miradas particulares de los investigadores. Sin desconocer el aporte de estos trabajos, también se percibe una tendencia a procesos colectivos que incluyen convocatorias abiertas y ejercicios de participación ciudadana, los cuales han producido resultados satisfactorios y muestran una metodología eficaz para futuras investigaciones.

A pesar de compartir objetivos similares, los proyectos revisados fueron desarrollados con diseños metodológicos diversos, que van desde el uso exclusivo de herramientas como la fotografía hasta la aplicación de encuestas, entrevistas y exhaustiva observación. De igual forma, se reconocen metodologías experimentales, basadas en convocatorias colectivas o apoyadas en procesos artísticos para analizar la ciudad, con resultados igualmente pertinentes.

El libro resultado de investigación y la web son los medios más usados en la publicación y divulgación de las investigaciones. Es notable la búsqueda de medios que permitan ir más allá de la difusión de resultados y de procesos de recolección de información, como también los ejercicios gráficos y visuales en torno a los proyectos. El libro y los entornos interactivos son idóneos para la difusión de estos.

La revisión mostró que en América Latina y en Colombia estas experiencias tienen gran acogida entre los investigadores. Para cada sentido fue posible relacionar uno o más proyectos llevados a cabo en el contexto local, lo cual aporta a la construcción de identidad y a la identificación de una estética propia, lejos de la homogeneidad usualmente causada por la transformación y el progreso de las ciudades. 


\section{REFERENCIAS BIBLIOGRÁFICAS}

Altamirano, L. (14 de enero de 2013). Paisajes sonoros de los barrios de ciudad de México. Recuperado el 22 de noviembre de 2015, de Revista Bifurcaciones: http://www.bifurcaciones.cl

Barbosa, L. J., Velázquez Osorio, J. \& Suárez Quintero, S. (2012). Entre lo puro e impuro: representaciones iconográficas en Bogotá. En L. J. Barbosa (Ed.). Conversaciones acerca de la fotografía (pp. 12-16). Tunja: Universidad de Boyacá.

Calvino, I. (2012). Las ciudades invisibles (Vol. 3). Madrid: Siruela.

Castro Herrera, E. (2013). 200 Efectos de sonidos urbanos de la ciudad de Bogotá. Universidad El Bosque, Formación musical. Bogotá: Universidad El Bosque.

Echeverri Arango, N. (2007). Expresiones estéticas del hábitat dentro de una comunidad barrial en transformación: La Piel del Morro. Medellín: Universidad Nacional de Colombia.

El Tiempo - Zona. (2014). El Tiempo. Recuperado el 15 de noviembre de 2015, de ¿A qué huele Bogotá?: https://app.eltiempo/multimedia/infografias/a-que-huele-bogota/14672083

García Canclini, N. (2010). De la comida al monumento: lo intercultural más allá de los rituales. Recuperado el 9 de julio de 2013, de http://nestorgarciacanclini.net/index.php?option=com_content\&view=article\&id=130:dela-comidangc\&catid=36:estetica-y-antropologia\&Itemid=56

Goldaracena, D. (2013). Daniel Goldaracena. Recuperado el 25 de octubre de 2013, de Book of sounds: http:// danielgoldaracena.com

Guerrero, Y. (2012). De la ciudad me sé su olor: aproximaciones visuales y otros sentidos, Tunja. Tunja: Universidad de Boyacá.

Hamann, H. (2001). New York Vertical. Mannheim, Alemania: Edition Panorama.

Mc Lean, K. (2014). Smell Map Narratives of Place - Paris. NANO New American Notes Online (6). 
Meléndez, M. (2012). Análisis iconográfico del almuerzo popular “corrientazo" en la ciudad de Bogotá a partir de los conceptos percepto y afecto de Gilles Deleuze. En Unitec (Ed.). Memorias 2o Encuentro Interdisciplinario de Grupos de Investigación. Arte, Ciencia, Tecnología e Innovación (pp. 41-64). Bogotá: Unitec.

Miralda, A. \& Guillén, M. (2011). Food cultura. Recuperado el 9 de julio de 2013, de http://www.foodcultura.org/

Museo de Bogotá. (2005). Paul Beer Metamorfosis de una ciudad. Bogotá: Alcaldía Mayor de Bogotá - Instituto Distrital de Cultura y Turismo.

Páez, A., \& Hernández, C. (2014). Son tus aromas: Bogotá. Nota Uniandina (43), 2 - 4.

Popular de Lujo. (2000a). Mesa 19. Recuperado el 9 de agosto de 2013, de www.populardelujo.com

Popular de Lujo. (2000b). Eres lo que comes. Recuperado el 9 de agosto de 2013, de www.populardelujo.com

Salas Silva, C., Ávila, J. \& Quiroz, F. (2003). Bogotá, cinco sentidos. Bogotá: Fuga.

Señal Colombia Sistema de Medios Públicos. (2013). 200 sonidos urbanos de la ciudad de Bogotá estarán en el Mapa sonoro. Recuperado de http://www.senalmemoria.gov.co

Silva, A. (2003). Bogotá imaginada. Bogotá: Taurus.

Sonema. (2013). Bogotá fonográfica. Bogotá: Laguna Libros.

Sonema. (2013). Sonema. Recuperado el 8 de noviembre de 2013, de http://www.sonema.org

Velázquez Osorio, J. (2010). Metáforas e íconos de la carne en Bogotá. Recuperado el 5 de julio de 2013, de www.julianvelasquez.com/wp-content/uploads/2010/09/METÁFORAS-E-ICÓNOS-DE-LA-CARNEEN-BOGOTA.pdf 